\title{
PAPER
}

\section{Probing Criegee intermediate reactions with methanol by FTMW spectroscopy $\dagger$}

\begin{abstract}
Carlos Cabezas ${ }^{a}$ and Yasuki Endo*b
Criegee intermediates (Cls) are carbonyl oxides generated from ozonolysis of unsaturated hydrocarbons in the atmosphere. The relatively long lifetime of $\mathrm{Cls}$ makes possible the bimolecular reactions with other atmospheric agents. These reactions can potentially be fast enough to contribute significantly to the tropospheric budgets of those species or to alter the rate of generation of secondary organic aerosols (SOAs). In particular, the new adducts formed in these reactions contribute SOA formation because they have larger molecular weights and lower vapor pressures than the reactants and are more condensable. $\alpha$-alkoxyalkyl hydroperoxides are the nascent products derived from the insertion reactions of $\mathrm{Cls}$ with alcohols. In this work we report the direct detection of methoxymethyl hydroperoxide $\left(\mathrm{HOOCH}_{2} \mathrm{OCH}_{3}, \mathrm{MMHP}\right)$ and methoxyethyl hydroperoxide $\left(\mathrm{HOOC}\left(\mathrm{CH}_{3}\right) \mathrm{HOCH}_{3}, \mathrm{MEHP}\right)$ as the reaction products between the $\mathrm{Cls}, \mathrm{CH}_{2} \mathrm{OO}$ and $\mathrm{CH}_{3} \mathrm{CHOO}$ and methanol. High resolution Fourier transform microwave spectroscopy has been used to identify one and two conformers of MMHP and MEHP, respectively. The pre-reactive complex $\mathrm{CH}_{2} \mathrm{OO}-\mathrm{CH}_{3} \mathrm{OH}$ was not observed in this experiment, which indicates that $\mathrm{CH}_{2} \mathrm{OO}$ shows a different reactivity toward methanol than that toward water. Our results for $\mathrm{CH}_{3} \mathrm{CHOO}+\mathrm{CH}_{3} \mathrm{OH}$ show that MEHP is produced in similar ratios when syn- and anti- $\mathrm{CH}_{3} \mathrm{CHOO}$ react with methanol vapor.
\end{abstract}

\section{Introduction}

Criegee intermediates (CIs) are reactive species formed in the ozonolysis of alkenes. ${ }^{1}$ Their formation is attributed to ring-opening of primary ozonides (POZs) formed directly by the 1,3-cycloaddition reaction of ozone across the olefinic bond. Nascent CIs possess a range of internal energies, a varying proportion of which possess sufficient excitation for prompt decomposition. The remainder of CIs collisionally stabilized, named stabilized Criegee intermediates (SCIs), will be sufficiently long-lived with respect to unimolecular processes that they may also engage in bimolecular reactions with several atmospheric species. Hence, the subsequent chemistry of SCIs is related to the atmospheric cycles of species such as $\mathrm{NO}_{x}$ and $\mathrm{HO}_{x}$ or to the secondary organic aerosols (SOAs), which are formed by their reaction towards $\mathrm{H}_{2} \mathrm{O},{ }^{2-4} \mathrm{SO}_{2}{ }^{5-7}$ or carboxylic acids. $^{8,9}$

\footnotetext{
${ }^{a}$ Instituto de Física Fundamental (IFF-CSIC), Group of Molecular Astrophysics, C/Serrano 121, 28006 Madrid, Spain

${ }^{b}$ Department of Applied Chemistry, Science Building II, National Chiao Tung University, 1001 Ta-Hsueh Rd., Hsinchu 30010, Taiwan.

E-mail: endo@nctu.edu.tw

$\dagger$ Electronic supplementary information (ESI) available: The optimized geometries for all the considered species and the measured transition frequencies for the detected ones.
}

Alcohols are a prevalent class of oxygenated volatile organic compounds (OVOCs) in the atmosphere and have terrestrial biogenic sources of which tropical rainforests are among the largest. ${ }^{10}$ Methanol is the most abundant alcohol in the troposphere. ${ }^{11,12}$ In fact it is the most abundant organic compound after methane. ${ }^{13-15}$ Because of the high flux of SCIs, co-location is expected between methanol and SCIs in the troposphere, and then reactions involving both species could have important atmospheric implications. These CIs with methanol is known to produce $\alpha$-methoxyalkyl hydroperoxides ${ }^{16}$ (MAHPs, Scheme 1) in a reaction that can be viewed as an effective insertion of the carbonyl oxide into the $\mathrm{O}-\mathrm{H}$ bond, similar to the reaction between CIs with water. MAHPs are a potential source of $\mathrm{OH}$ radicals and may be significant in terms of the SOAs formation in the troposphere. ${ }^{17-19}$

Just in the last three years, several works have been devoted to investigate the reactions between CIs and alcohols, especially

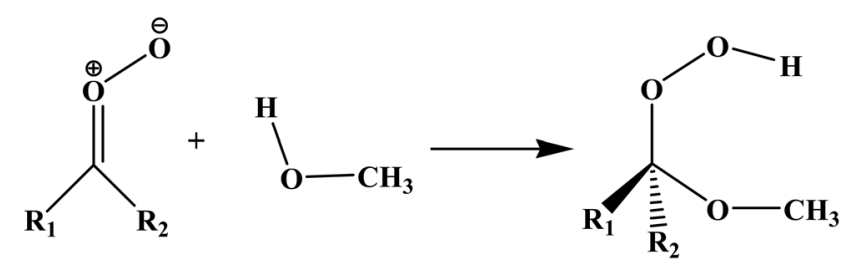

Scheme 1 Formation of MAHPs from Criegee intermediates. 
those with methanol. McGillen et al. ${ }^{19}$ reported the rate coefficients for the reactions of $\mathrm{CH}_{2} \mathrm{OO}$ and $\left(\mathrm{CH}_{3}\right)_{2} \mathrm{COO}$ with methanol and that of $\mathrm{CH}_{2} \mathrm{OO}$ with ethanol, and found that substitution on the Criegee intermediate has a strong influence over the reaction rate, whereas substitution on the alcohol moiety does not. Similar conclusion was reached by Tadayon et $a{ }^{20}{ }^{20}$ who investigated the reactions between $\mathrm{CH}_{2} \mathrm{OO}$ and methanol, ethanol, and 2-propanol. More recently the reactivity of the singly methyl substituted $\mathrm{CI}, \mathrm{CH}_{3} \mathrm{CHOO}$, towards methanol has been investigated by Lin et al. ${ }^{21}$ and Chao et al. ${ }^{22}$ These authors found that the reaction of $s y n-\mathrm{CH}_{3} \mathrm{CHOO}$ with methanol is enhanced by a single water molecule under ambient conditions. In addition, they observed a competing channel of syn- $\mathrm{CH}_{3} \mathrm{CHOO}+2 \mathrm{CH}_{3} \mathrm{OH}$ and evaluated the kinetic isotopic effects for the reactions. Alcohol-CI reactions have also been explored using quantum chemical calculations. Aroeira et al. ${ }^{23}$ studied the reactions of $\mathrm{CH}_{2} \mathrm{OO}$ and $\left(\mathrm{CH}_{3}\right)_{2} \mathrm{COO}$ with methanol employing rigorous $a b$ initio methods while Watson et al. ${ }^{24}$ have performed the most comprehensive computational study of alcohol-CI reactions including up to 22 different CIs.

In this paper we describe a combined experimental and computational study of the reactions between the simplest CI, $\mathrm{CH}_{2} \mathrm{OO}$, and its methyl derivative, $\mathrm{CH}_{3} \mathrm{CHOO}$, towards methanol. The nascent products resulting from these two reactions have been characterized using high resolution Fourier transform microwave spectroscopy in combination with electric discharges. Complementary high level $a b$ initio calculations have been performed to map out the reaction pathways and to identify the nature of the reaction products. The reactivity trend of each $\mathrm{CH}_{3} \mathrm{CHOO}$ conformer is derived from the intensity of their rotational spectra, and it is compared to previously reported results.

\section{Quantum chemical calculations}

Quantum chemical calculations on the reactions of $\mathrm{CH}_{2} \mathrm{OO}$ and $\mathrm{CH}_{3} \mathrm{CHOO}$ with $\mathrm{CH}_{3} \mathrm{OH}$ have been reported previously. ${ }^{19-24}$
However, to ascertain the relative stabilities of the plausible products of these reactions and estimate the rotational parameters necessary to interpret their rotational spectra, we have carried out new ab initio calculations. All stationary points on the reaction pathways explored in this study were fully optimized using the coupled cluster singles and doubles correlated (CCSD) method along with Dunning's augmented correlation consistent polarized valence triple- $\zeta$ (aug-cc-pVTZ) basis set. ${ }^{25}$ The transition states and the minima were mapped using the Quadratic Steepest Descent reaction path. ${ }^{26}$ All the calculations were carried out using the Molpro 2018.1 ab initio program package. $^{27}$

Fig. 1 illustrates the reaction pathways between $\mathrm{CH}_{2} \mathrm{OO}$ and $\mathrm{CH}_{3} \mathrm{CHOO}$ with $\mathrm{CH}_{3} \mathrm{OH}$ that lead the formation of methoxymethyl hydroperoxide $\left(\mathrm{HOOCH}_{2} \mathrm{OCH}_{3}, \mathrm{MMHP}\right)$ and methoxyethyl hydroperoxide ( $\left.\mathrm{HOOC}\left(\mathrm{CH}_{3}\right) \mathrm{HOCH}_{3}, \mathrm{MEHP}\right)$, respectively. The first step is the formation of the pre-reactive complex (PRC) which is stabilized by a hydrogen-bonding interaction between $\mathrm{CH}_{3} \mathrm{OH}$ hydrogen and the carbonyl oxide terminal oxygen. After complexation, the reactants are positioned for the insertion of the carbonyl oxide into the alcohol $\mathrm{O}-\mathrm{H}$ bond, which can proceed for two different pathways. Hence, each $\mathrm{CI}-\mathrm{CH}_{3} \mathrm{OH}$ insertion reaction exhibits two different transitions states, distinguished by the orientation of the $\mathrm{CH}_{3} \mathrm{OH}$ molecule relative to the CI, giving rise to two different MAHP conformations. Fig. 2 and 3 show the molecular structures for all the stationary points, including pre-reactive complexes, transitions states and products, for the $\mathrm{CH}_{3} \mathrm{OH}$ reactions with $\mathrm{CH}_{2} \mathrm{OO}$ and $\mathrm{CH}_{3} \mathrm{CHOO}$, respectively.

In the case of the syn- $\mathrm{CH}_{3} \mathrm{CHOO}+\mathrm{CH}_{3} \mathrm{OH}$ another reaction pathway can produce vinyl hydroperoxide $\left(\mathrm{CH}_{2}=\mathrm{CHOOH}\right)$, VHP. It consists of an exothermic process where the methanol molecule facilitates the hydrogen transfer from the $\alpha$-methyl group to the carbonyl oxide terminal oxygen through a double hydrogen shift. This reaction pathway has not been considered in the present work because the formation of VHP is less favorable than the resulting products formed in the insertion
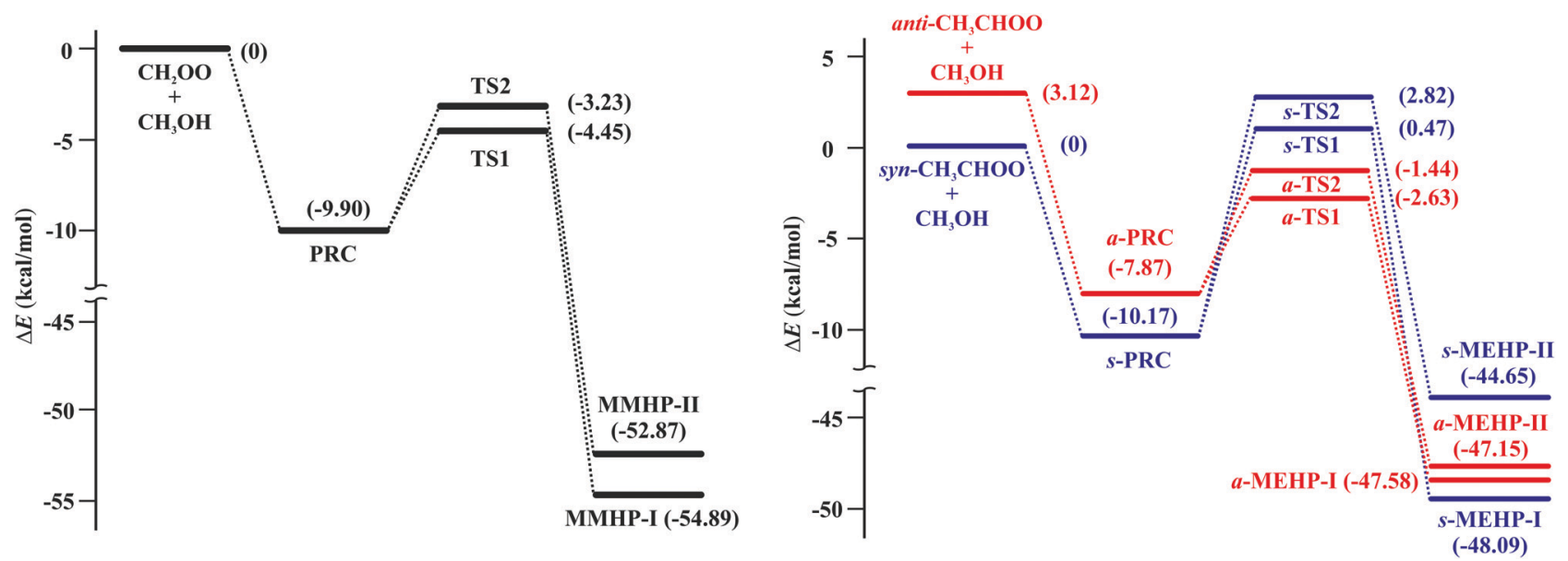

Fig. 1 Energy diagrams for the $\mathrm{CH}_{2} \mathrm{OO}+\mathrm{CH}_{3} \mathrm{OH}$ (left) and $\mathrm{CH}_{3} \mathrm{CHOO}+\mathrm{CH}_{3} \mathrm{OH}$ (right) reactions. All the calculations were performed at the CCSD/ aug-cc-pVTZ level of theory. Total energies relative to those of separated molecules are given in parentheses (in $\mathrm{kcal}^{\mathrm{mol}}{ }^{-1}$ ). 


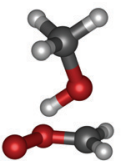

PRC

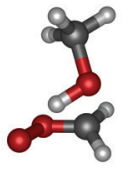

TS1

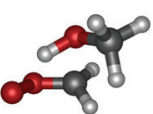

TS2
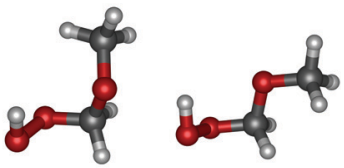

MMHP-I MMHP-II

Fig. 2 Molecular structures for all the stationary points, including prereactive complex, transition states and products, for the $\mathrm{CH}_{2} \mathrm{OO}+\mathrm{CH}_{3} \mathrm{OH}$ reaction.
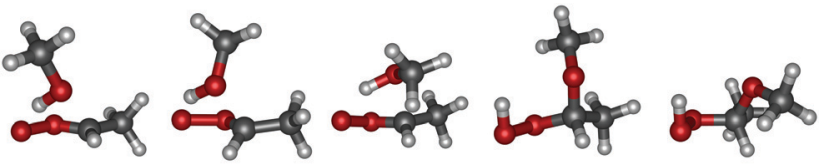

$a$-PRC $a$-TS1 $a$-TS2 $a$-MEHP-I $a$-MEHP-II
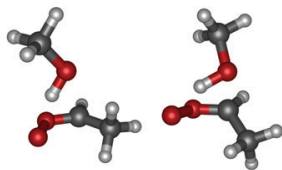

$s$-PRC
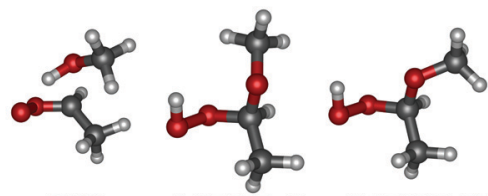

$s$-TS2 s-MEHP-I s-MEHP-II
Fig. 3 Molecular structures for all the stationary points, including prereactive complexes, transition states and products, for the $\mathrm{CH}_{3} \mathrm{CHOO}+$ $\mathrm{CH}_{3} \mathrm{OH}$ reaction.

reaction, ${ }^{24}$ as it occurs in the $s y n-\mathrm{CH}_{3} \mathrm{CHOO}+\mathrm{HCOOH}$ reaction. ${ }^{28-30}$

According to our calculations, the two and four conformers of MMHP and MEHP, respectively, are potentially observable by FTMW spectroscopy since their formation reactions are all exothermic. Accurate molecular rotational constants and electric dipole moment components are necessary to predict the rotational transition frequencies of these species. The values obtained for these parameters at CCSD/aug-cc-pVTZ level of theory are summarized in Tables 1 and 2 .

\section{Experimental}

The experimental apparatus employed in this investigation has been described in a previous work. ${ }^{31}$ It consists of a BalleFlygare type Fourier-transform cavity microwave spectrometer ${ }^{32}$

Table 1 Rotational constants and electric dipole moment components for the two MMHP conformers calculated at the CCSD/aug-cc-pVTZ level of theory

\begin{tabular}{lll}
\hline & MMHP-I & MMHP-II \\
\hline$A / \mathrm{MHz}$ & 10990 & 13718 \\
$B / \mathrm{MHz}$ & 3241 & 2942 \\
$C / \mathrm{MHz}$ & 3103 & 2662 \\
$\left|\mu_{\mathrm{a}}\right| / \mathrm{D}^{a}$ & 2.20 & 2.91 \\
$\left|\mu_{\mathrm{b}}\right| / \mathrm{D}$ & 0.18 & 0.20 \\
$\left|\mu_{\mathrm{c}}\right| / \mathrm{D}$ & 0.26 & 0.71 \\
$\Delta E / \mathrm{kcal} \mathrm{mol}^{-1}$ & $0^{b}$ & 2.02
\end{tabular}

${ }^{a} 1 \mathrm{D} \approx 3.3356 \times 10^{-30} \mathrm{C} \mathrm{m} \cdot{ }^{b}$ Relative energy to that of MMHP-I species.
Table 2 Rotational constants and electric dipole moment components for the four MEHP conformers calculated at the CCSD/aug-cc-pVTZ level of theory

\begin{tabular}{lllll}
\hline & $a$-MEHP-I & $a$-MEHP-II & $s$-MEHP-I & $s$-MEHP-II \\
\hline$A / \mathrm{MHz}$ & 4688 & 3963 & 4757 & 5753 \\
$B / \mathrm{MHz}$ & 3120 & 3565 & 3065 & 2604 \\
$C / \mathrm{MHz}$ & 2230 & 2057 & 2264 & 2155 \\
$\left|\mu_{\mathrm{a}}\right| / \mathrm{D}^{a}$ & 2.38 & 2.08 & 2.04 & 2.72 \\
$\left|\mu_{\mathrm{b}}\right| / \mathrm{D}$ & 0.26 & 0.08 & 0.48 & 0.10 \\
$\mid \mu_{\mathrm{c}} / / \mathrm{D}$ & 0.23 & 0.51 & 0.02 & 0.52 \\
$\Delta E / \mathrm{kcal} \mathrm{mol}^{-1}$ & $0.50^{b}$ & 0.94 & 0 & 3.44
\end{tabular}

${ }^{a} 1 \mathrm{D} \approx 3.3356 \times 10^{-30} \mathrm{C} \mathrm{m} \cdot{ }^{b}$ Relative energy to that of $s$-MEHP-I species.

operating in the $4-40 \mathrm{GHz}$ frequency region. It is equipped with a pulsed discharge nozzle $e^{33,34}$ and a double-resonance setup. ${ }^{35}$ The frequency measurements have an estimated accuracy better than $3 \mathrm{kHz}$ and the resolution is better than $5 \mathrm{kHz}$.

In the study of the $\mathrm{CH}_{2} \mathrm{OO}+\mathrm{CH}_{3} \mathrm{OH}$ reaction the short-lived species were produced in the throat of an electrical discharge of a gas mixture of 1,1-diiodomethane, methanol and oxygen heavily diluted in argon. The gas mixture of $0.3 \%$ methanol, $2 \% \mathrm{O}_{2}$ and $97.7 \%$ Ar with the total pressure of 1.5 atm was passed through a container filled with liquid 1,1-diiodomethane in order to introduce the precursor molecules with sufficient partial pressures. In the case of $\mathrm{CH}_{3} \mathrm{CHOO}, 1,1$-diiodomethane was replaced by 1,1-diiodoethane, and other experimental conditions were identical. The gas mixture was flowed through a pulsed-solenoid valve that is accommodated in the backside of one of the cavity mirrors and aligned parallel to the optical axis of the resonator. A pulsed voltage of $1.0 \mathrm{kV}$ with $450 \mu \mathrm{s}$ of duration was applied between electrodes attached at the exit of the nozzle to induce an electric discharge, synchronized with the gas expansion, which triggers the chemical reactions in the precursor mixture. The resulting products generated in the discharge are supersonically expanded and rapidly cooled to a rotational temperature of $\sim 2 \mathrm{~K}$ and probed by FTMW spectroscopy. Further experiments were carried out with the monodeuterated species of methanol, $\mathrm{CH}_{3} \mathrm{OD}$, which was prepared by mixing $\mathrm{CH}_{3} \mathrm{OH}$ and $\mathrm{D}_{2} \mathrm{O}$.

\section{Results}

\section{$\mathrm{CH}_{2} \mathrm{OO}+\mathrm{CH}_{3} \mathrm{OH}$}

As mentioned before, the target species to be found in the rotational spectrum are the two conformers of MMHP. Prior to the search for these species we checked the production of $\mathrm{CH}_{2} \mathrm{OO}$, and during all the experiments a very strong signal was observed for the $1_{01}-0_{00}$ pure rotational transition of $\mathrm{CH}_{2} \mathrm{OO}$ at $23186.49 \mathrm{MHz},{ }^{36}$ indicating an efficient production of $\mathrm{CH}_{2} \mathrm{OO}$ in the discharged jet.

Referring to the predicted dipole moment components, both MMHP conformers will show strong $a$-type rotational spectrum. Hence, first experiments were devoted to scan the frequency interval between 12 and $15 \mathrm{GHz}$ searching for $a$-type transitions for both conformers. In the initial scans we observed strong 

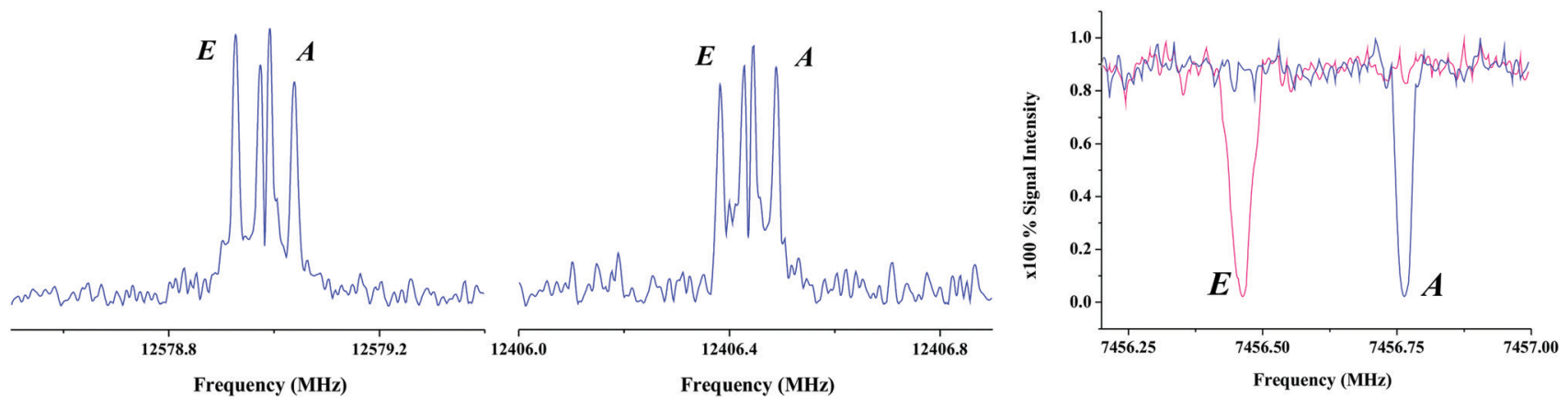

Fig. 4 The FTMW spectra of the $2_{02}-1_{01}$ rotational transitions for the parent species of MMHP-I (left) conformer and $d-M M H P-I$ (center) with $A$ and $E$ components indicated, obtained using 100 accumulation shots. (Right) FTMW-MW double resonance spectra of $2_{12}-2_{02}$ rotational transition of MMHP-I conformer showing the $A$ and $E$ internal rotation components. $A$ and $E$ components of the $2_{02}-1_{01}$ at 12579.015 and $12578.950 \mathrm{MHz}$, respectively, were used to monitor the $A$ and $E$ components of $2_{12}-2_{02}$ rotational transition, respectively.

signals that appeared close to the predicted rotational frequencies for the MMHP-I conformer. These lines, identified as $2_{12}-1_{11}, 2_{02}-1_{01}$ and $2_{11}-1_{10}$, appeared split into two components, $A$ and $E$, as a result of the interaction between the molecular overall and internal rotations ${ }^{37}$ (Fig. 4). MW-MW double-resonance experiments were used for observing additional transitions and thus confirming the assignments of those observed by FTMW spectroscopy (Fig. 4). Very weak $b$ - and $c$-type transitions were also observed. Finally a total of 20 pure rotational transitions were measured for this species. All the observed rotational frequencies for $A$ and $E$ components (see ESI $\dagger$ ) were included in a least-squares fit using the XIAM program ${ }^{38}$ which is based on the combined axis method with the form given by Woods. ${ }^{39}$ The analysis rendered the experimental rotational constants together with the internal rotation parameters listed in Table 3 . No lines remain unassigned in the scanned regions after the identification of those for the MMHP-I conformer.

The use of deuterated methanol in the further experiments served to confirm the identity of the observed species and the

Table 3 Experimental rotational parameters for the observed species of MMHP and its deuterated isotopologue

\begin{tabular}{lll}
\hline & MMHP-I & $d$-MMHP-I \\
\hline$A / \mathrm{MHz}$ & $10817.34317(86)^{f}$ & $10411.89297(30)$ \\
$B / \mathrm{MHz}$ & $3217.88152(40)$ & $3188.24842(61)$ \\
$C / \mathrm{MHz}$ & $3072.69696(43)$ & $3016.53857(62)$ \\
$\Delta_{J} / \mathrm{kHz}$ & $3.8751(84)$ & $4.106(35)$ \\
$\Delta_{J K} / \mathrm{kHz}$ & $-30.519(45)$ & {$[-30.519]^{g}$} \\
$\delta_{J} / \mathrm{kHz}$ & $0.6532(80)$ & {$[0.6532]$} \\
$V_{3} / \mathrm{cm}^{-1}$ & $541.73(37)$ & {$[541.73]$} \\
$F_{0}{ }^{a} / \mathrm{GHz}$ & 154.597 & 154.597 \\
$\delta^{b} / \mathrm{rad}$ & $0.8771(26)$ & {$[0.8771]$} \\
$\varepsilon^{c} / \mathrm{rad}$ & $2.030(14)$ & {$[2.030]$} \\
$N^{d}$ & 40 & 12 \\
$\sigma^{e} / \mathrm{kHz}$ & 2.4 & 2.6
\end{tabular}

${ }^{a}$ Rotational constant of the methyl top. Fixed to the $a b$ initio value. ${ }^{b}$ Angle between the principal axis ( $a$-axis) of the molecule and the internal rotation axis. ${ }^{c}$ Angle between the principal axis ( $a$-axis) of the molecule and the projection of the internal rotation axis onto $b c$-plane. ${ }^{d}$ Number of pure rotational transitions included in the fit. ${ }^{e}$ Standard deviation of the fit. ${ }^{f}$ Values in parentheses denote $1 \sigma$ errors, applied to the last digit. ${ }^{g}$ Values in brackets refer to values fixed to the those obtained for the parent species. nature of its formation. By replacing $\mathrm{CH}_{3} \mathrm{OH}$ by $\mathrm{CH}_{3} \mathrm{OD}$, we observed rotational transitions for $d$-MMHP-I species $\left(\mathrm{DOOCH}_{2} \mathrm{OCH}_{3}\right)$, where the terminal hydrogen atom in MMHP is substituted by a deuterium atom, which comes from the methanol molecule. The rotational transitions for $d$-MMHP-I species show the $A-E$ splitting like in the parent species. However, no hyperfine effects due to the presence of a deuterium nucleus, with the nuclear quadrupole moment different from zero $(I=1)$, were observed, as seen in Fig. 4. The observed transitions were analyzed using the XIAM program $^{38}$ and the derived experimental parameters for $d$-MMHP-I species are shown in Table 3 .

\section{$\mathrm{CH}_{3} \mathrm{CHOO}+\mathrm{CH}_{3} \mathrm{OH}$}

As can be seen in Fig. 1, formation of the four MEHP species is exothermic and seems to be as favorable as in the case of the $\mathrm{CH}_{2} \mathrm{OO}+\mathrm{CH}_{3} \mathrm{OH}$ reaction. During these experiments, strong signals of the $1_{01}-0_{00}$ and $2_{02}-1_{01}$ pure rotational transitions of syn- $\mathrm{CH}_{3} \mathrm{CHOO}$ and anti- $\mathrm{CH}_{3} \mathrm{CHOO}$ species were observed at $12362.64 \mathrm{MHz}^{40}$ and $17202.53 \mathrm{MHz}^{41}$ respectively, confirming the formation of $\mathrm{CH}_{3} \mathrm{CHOO}$ in the discharged jet.

We followed the same strategy used for the MMHP since both species have appreciable $\mu_{\mathrm{a}}$ dipole moments. In this manner, we found two series of $a$-type rotational transitions which were finally assigned to the $a$-MEHP-I and $s$-MEHP-I species. For the former a total of $12 a$-type pure rotational transitions were observed, while 19 transitions, including $a$ - and $b$-types, were measured for the latter one. In spite of the fact that both the $a$-MEHP-I and $s$-MEHP-I species have comparable $\mu_{\mathrm{b}}$ dipole moment components, the weaker spectrum observed for the $a$-MEHP-I species hampered the observation of $b$-type transitions. Fig. 5 illustrates the $4_{04}-3_{03}$ rotational transitions observed for $a$-MEHP-I and $s$-MEHP-I, which show $A-E$ splitting due to the methyl internal rotation. Analyses of the rotational transitions were carried out using the XIAM program $^{38}$ and the derived experimental parameters are depicted in Table 4. No lines remain unassigned in the spectra when all the lines for the $a$-MEHP-I and $s$-MEHP-I conformers were identified. Therefore, no more MEHP species could be observed. 


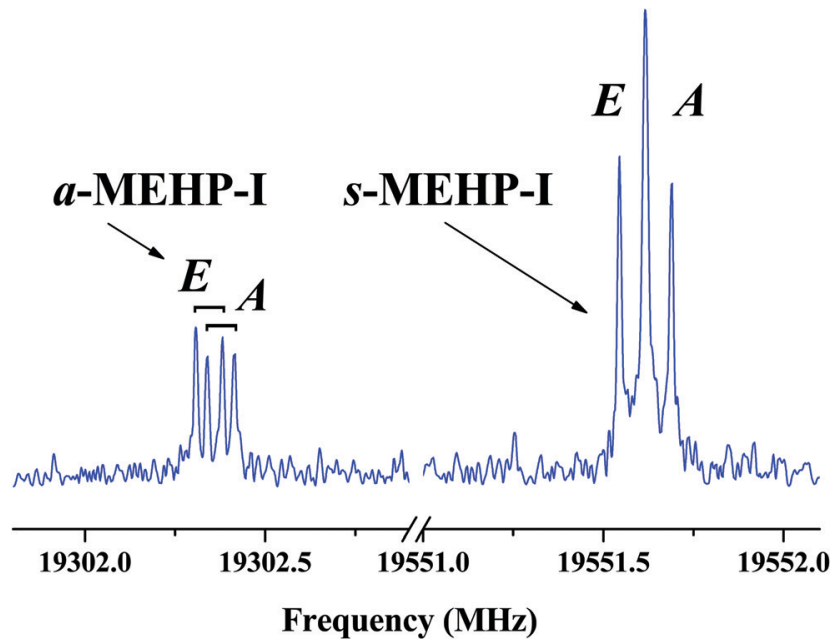

Fig. 5 The FTMW spectra of the $4_{04}-3_{03}$ rotational transitions for the parent species of a-MEHP-I and S-MEHP-I conformers showing the $A$ and $E$ components. Both spectra were obtained using 100 accumulation shots.

Table 4 Experimental rotational parameters for the observed conformers of MEHP the isotopic species

\begin{tabular}{llll}
\hline & $a$-MEHP-I & $s$-MEHP-I & $\mathrm{d}$-s-MEHP-I \\
\hline$A / \mathrm{MHz}$ & $4605.7969(36)^{f}$ & $4691.0497(17)$ & $4560.0829(37)$ \\
$B / \mathrm{MHz}$ & $3113.83864(85)$ & $3055.90066(60)$ & $3029.49989(27)$ \\
$C / \mathrm{MHz}$ & $2212.39680(54)$ & $2248.63486(42)$ & $2222.93333(26)$ \\
$\Delta_{J} / \mathrm{kHz}$ & $1.849(14)$ & $1.705(11)$ & $1.7645(50)$ \\
$\Delta_{J K} / \mathrm{kHz}$ & $-4.50(11)$ & $-3.181(59)$ & {$[-3.181]^{h}$} \\
$\Delta_{K} / \mathrm{kHz}$ & - & $5.90(33)$ & {$[5.90]$} \\
$\delta_{J} / \mathrm{kHz}$ & $0.6815(98)$ & $0.5710(52)$ & {$[0.5710]$} \\
$\delta_{K} / \mathrm{kHz}$ & - & $0.96(10)$ & {$[0.96]$} \\
$V_{3} / \mathrm{cm}{ }^{-1}$ & $650.8(36)$ & $549.00(37)$ & {$[549.00]$} \\
$F_{0}{ }^{a} / \mathrm{GHz}$ & 153.610 & 161.825 & 161.825 \\
$\delta^{b} / \mathrm{rad}$ & $0.994^{g}$ & $0.6962(36)$ & {$[0.6962]$} \\
$\varepsilon^{c} / \mathrm{rad}$ & $2.211(35)$ & $2.6191(91)$ & {$[2.6191]$} \\
$N^{d}$ & 24 & 38 & 18 \\
$\sigma^{e} / \mathrm{kHz}$ & 2.7 & 2.0 & 1.7
\end{tabular}

${ }^{a}$ Rotational constant of the methyl top. Fixed to the $a b$ initio value. ${ }^{b}$ Angle between the principal axis ( $a$-axis) of the molecule and the internal rotation axis. ${ }^{c}$ Angle between the principal axis ( $a$-axis) of the molecule and the projection of the internal rotation axis onto $b c$-plane. ${ }^{d}$ Number of pure rotational transitions included in the fit. ${ }^{e}$ Standard deviation of the fit. ${ }^{f}$ Values in parentheses denote $1 \sigma$ errors, applied to the last digit. ${ }^{g}$ Fixed to the ab initio value. ${ }^{h}$ Values in brackets refer to values fixed to the those obtained for the parent species.

We carried out experiments using deuterated methanol species to confirm the identity of the observed species. We could measure rotational transitions for the d-s-MEHP-I species, $\left(\mathrm{DOOC}\left(\mathrm{CH}_{3}\right) \mathrm{HOCH}_{3}\right)$. The experimental parameters determined by the analysis of the spectrum are shown in Table 4 . We tried to observe the spectrum for the analogous d- $a$-MEHP-I but the trials resulted unfruitful due to the low intensity of the lines.

\section{Discussion}

\section{$\mathrm{CH}_{2} \mathrm{OO}+\mathrm{CH}_{3} \mathrm{OH}$}

The identification of MMHP-I was assisted by the quantum chemical calculations. A good agreement between the experimental and theoretical rotational constants was found, with maximum relative deviations of about $1.5 \%$ for the $A$ rotational constant. The assignment of the MMHP-I conformer is reinforced by the observation of the deuterated species $d$-MMHP-I when $\mathrm{CH}_{3} \mathrm{OD}$ species is used. This observation also confirms that MMHP is formed via the insertion of $\mathrm{CH}_{2} \mathrm{OO}$ into the methanol $\mathrm{O}-\mathrm{H}$ bond ( $\mathrm{O}-\mathrm{D}$ bond when $\mathrm{CH}_{3} \mathrm{OD}$ is used). Conformer MMHP-II was not observed in our experiments in spite of the fact that exhaustive spectral searches were carried out. The non-observation of the MMHP-II species can be explained from both kinetic and thermodynamical points of view. The MMHP-I and MMHP-II conformers are formed through independent insertion mechanisms differing only in the TS, which is $\sim 0.8 \mathrm{kcal} \mathrm{mol}^{-1}$ more stable in the case of the MMHP-I pathway. In addition, the MMHP-I formation is $\sim 2 \mathrm{kcal} \mathrm{mol}^{-1}$ more exothermic than that for MMHP-II. Although kinetic and thermodynamic data favor the formation of the MMHP-I conformer, the energetic differences of the TSs and the products are tiny compared with the overall exothermicity of the reactions. Our experiments are carried out in a supersonic expansion, and this point must be taken into account since conformational interconversion may occur between the contemplated molecular species. These processes take place in the early stages of the supersonic expansion by collisions between different conformers and the buffer gas molecules. Ruoff $e$ e al $^{42}$ have deduced that collisional removal of a higher energy conformer is possible when the isomerization barrier is around $400-500 \mathrm{~cm}^{-1}$, when $\mathrm{Ar}$ is used as the carrier gas. In previous works we have reported conformational interconversion between CI species ${ }^{43}$ through a barrier height of $479 \mathrm{~cm}^{-1}$. As can be seen in Fig. 2, MMHP-I and MMHP-II conformers differ exclusively in the relative orientation of the disposition of the $-\mathrm{CH}_{3}$ group and then, they present different values of the dihedral angle $\angle$ OCOC. We calculated the potential energy profile for MMHP-II $\rightarrow$ MMHP-I interconversions by scanning the dihedral angle $\angle$ OCOC. An energy barrier of $415 \mathrm{~cm}^{-1}$ was found, which is not high enough to preclude the interconversion between these conformers (Fig. 6). Hence, this could be the main reason for the non-observation of conformer MMHP-II in our experiment, which could convert MMHP-II in MMHP-I during the early stages of the supersonic expansion.

The reactivity of $\mathrm{CH}_{2} \mathrm{OO}$ toward methanol can be compared to that toward water. Nakajima and Endo ${ }^{44,45}$ investigated the reaction between $\mathrm{CH}_{2} \mathrm{OO}$ and water using the same experimental technique as that employed in the present study. They observed coexistence of the $\mathrm{PRC}, \mathrm{CH}_{2} \mathrm{OO}-\mathrm{H}_{2} \mathrm{O}$, and the reaction product, hydroxymethyl hydroperoxide (HMHP) in the supersonic expansion. The observation of the PRC in the case of the water reaction is easily understood because the TS between the PRC and the reaction product is $9.2 \mathrm{kcal} \mathrm{mol}^{-1}$ above the PRC and $2.4 \mathrm{kcal} \mathrm{mol}^{-1}$ higher than the separated reactants. In the case of methanol, both TS1 and TS2 are submerged below the reactants and the PRC can easily overcome the TS barriers leading MMHP while little or none of the complexes can survive in the supersonic jet. The observation of MMHP-I species in the reaction of $\mathrm{CH}_{2} \mathrm{OO}+$ $\mathrm{CH}_{3} \mathrm{OH}$ is obvious in light of the energy results shown in Fig. 1. 


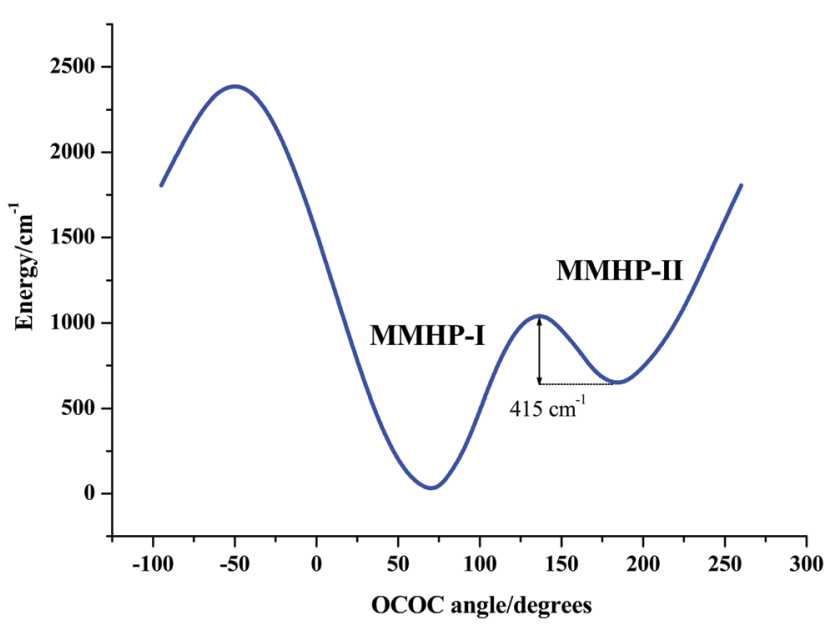

Fig. 6 Potential energy profile of MMHP around the $\angle O C O C$ dihedral angle calculated at CCSD/aug-cc-pVTZ level of theory.

On the other hand, for the formation of HMHP from the $\mathrm{CH}_{2} \mathrm{OO}+\mathrm{H}_{2} \mathrm{O}$ reaction it has been justified ${ }^{4,45-48}$ by the fact that the water dimer $\left(\mathrm{H}_{2} \mathrm{O}\right)_{2}$ plays a significant role reducing the TS energy. In such reaction, one $\mathrm{H}_{2} \mathrm{O}$ molecule of the dimer works just as a catalytic agent.

The analysis of the internal rotation splittings for the MMHP-I conformer allowed us to determine the experimental threefold methyl internal rotation barrier height $\left(V_{3}\right)$ and other structural parameters as collected in Table 3. The experimental values agree well with those predicted $a b$ initio which are collected in Table 5. The experimental value for the $V_{3}$ barrier, $541.73(37) \mathrm{cm}^{-1}$ is slightly larger than that predicted theoretically, $509.3 \mathrm{~cm}^{-1}$. Since $F_{0}$ value, which is associated with the moment of inertia of the methyl top, could not be determined in the present fit, it was fixed to the value derived from the $a b$ initio geometries. The experimental $V_{3}$ value found for MMHP-I is very similar to that found by Motiyenko et al. $^{49}$ for methoxymethanol molecule $\left(\mathrm{CH}_{3} \mathrm{OCH}_{2} \mathrm{OH}\right)$, which shares the $\mathrm{CH}_{3} \mathrm{OCH}_{2} \mathrm{O}$ moiety with MMHP-I $\left(\mathrm{CH}_{3} \mathrm{OCH}_{2} \mathrm{OOH}\right)$. The experimental $V_{3}$ value for methoxymethanol found by Motiyenko et al. is $545.92(39) \mathrm{cm}^{-1}$, only $0.8 \%$ larger than the value determined for MMHP-I in the present work. In absence of steric hindrances in both species, the $V_{3}$ barrier height seems to be governed by similar electronic factors.

Table 5 Theoretical internal rotation parameters for MMHP and MEHP observed conformers

\begin{tabular}{llll}
\hline & MMHP-I & $a$-MEHP-I & $s$-MEHP-I \\
\hline$V_{3}{ }^{a} / \mathrm{cm}^{-1}$ & 509.3 & 592.7 & 510.0 \\
$F_{0}{ }^{b} / \mathrm{GHz}$ & 154.597 & 153.610 & 161.825 \\
$\delta^{c} / \mathrm{rad}$ & 0.904 & 0.994 & 0.718 \\
$\varepsilon^{d} / \mathrm{rad}$ & 1.976 & 1.957 & 2.523
\end{tabular}

${ }^{a}$ Internal rotation barrier height calculated at CCSD/aug-cc-pVTZ level of theory. ${ }^{b}$ Rotational constant of the methyl top. ${ }^{c}$ Angle between the principal axis ( $a$-axis) of the molecule and the internal rotation axis. ${ }^{d}$ Angle between the principal axis ( $a$-axis) of the molecule and the projection of the internal rotation axis onto $b c$-plane.

\section{$\mathrm{CH}_{3} \mathrm{CHOO}+\mathrm{CH}_{3} \mathrm{OH}$}

As it occurs for MMHP-I, the agreement between the experimental and theoretical values of the rotational constants for MEHP conformers is very good, with maximum relative deviations of about $1.7 \%$ for the $A$ rotational constant in the case of $a$-MEHP-I. Similarly to the reaction between $\mathrm{CH}_{2} \mathrm{OO}+\mathrm{CH}_{3} \mathrm{OH}$, the reaction of each $s y n$ - and anti- $\mathrm{CH}_{3} \mathrm{CHOO}$ conformers with $\mathrm{CH}_{3} \mathrm{OH}$ gives the most stable products, $s$-MEHP-I and $a$-MEHP-I. The formation of $s$-MEHP-I species is preferred due to the fact that $s$-TS1 is lower than $s$-TS2 and $s$-MEHP-I is $\sim 4.4 \mathrm{kcal} \mathrm{mol}^{-1}$ more stable than $s$-MEHP-II. For the $a$-MEHP conformers the energy differences are smaller for the TSs and also between the products. However, the observed $a$-MEHP-I conformer is energetically preferred.

The relative abundances of $s$-MEHP-I and $a$-MEHP-I conformers can be estimated taking into account the observed spectral intensities of the $a$-type rotational transitions (Fig. 5). The intensity of each rotational transition is proportional to the number density of each conformer and the value of the corresponding component of the dipole moment, $N_{\mathrm{i}} \cdot \mu_{\mathrm{i}}$. Considering the predicted values of the dipole moment components (Table 2), the relative abundances have been found to be: $s$-MEHP-I : $a$-MHEP-I $=2.6: 1$, which roughly corresponds to the production ratio of $s y n-$ and anti- $\mathrm{CH}_{3} \mathrm{CHOO}$ under our experimental conditions where $\operatorname{syn}-\mathrm{CH}_{3} \mathrm{CHOO}$ is about five times more abundant than anti- $\mathrm{CH}_{3} \mathrm{CHOO} .^{40,41}$ This abundance ratio for $s$-MEHP-I/a-MHEP-I contrasts with the reaction paths from Fig. 1, where the $s$-PRC/s-TS1 energy gap is 2 times larger than that for $a$-PRC/ $a$-TS1 with $a$-TS1 submerged below the reactants while $s$-TS1 is slightly above the reactants. The inconsistency between the theory and our experimental results can be explained considering the termolecular reaction of syn- $\mathrm{CH}_{3} \mathrm{CHOO}+2 \mathrm{CH}_{3} \mathrm{OH}$. Chao et al. ${ }^{22}$ reported both experimentally and theoretically an enhancement on the reactivity of syn- $\mathrm{CH}_{3} \mathrm{CHOO}$ toward $\mathrm{CH}_{3} \mathrm{OH}$ when a second methanol molecule is involved in the reaction. The assistance of these molecules as catalysts is reflected in a large decrease in the energy gap PRC/TS, which increases the reactivity of syn$\mathrm{CH}_{3} \mathrm{CHOO}$ toward $\mathrm{CH}_{3} \mathrm{OH}$. As shown by Chao et al. ${ }^{22}$ the formation of $s$-MEHP-I proceeds via a 7-membered-ring transition state structure and the reaction involves transfer of the $\mathrm{H}$ atoms and formation of a CO bond. Hence, our experimental results can be understood after considering the termolecular reaction of $s y n-\mathrm{CH}_{3} \mathrm{CHOO}+2 \mathrm{CH}_{3} \mathrm{OH}$, which predominate over bimolecular reactions under certain conditions like in other $\mathrm{CI}$ reactions toward hydrogen-bonding molecules. Similar catalytic effects have been reported to occur when a second water molecule participates in the $\mathrm{CH}_{2} \mathrm{OO}+\mathrm{H}_{2} \mathrm{O}^{46-48}$ and anti- $\mathrm{CH}_{3} \mathrm{CHOO}+\mathrm{H}_{2} \mathrm{O}^{50}$ reactions.

The present results can be compared to those reported by Cabezas and Endo ${ }^{51}$ for the FTMW study of the $\mathrm{CH}_{3} \mathrm{CHOO}+$ $\mathrm{H}_{2} \mathrm{O}$ reaction. In that case, the syn $-\mathrm{CH}_{3} \mathrm{CHOO}-\mathrm{H}_{2} \mathrm{O}$ PRC was observed together with two conformers of hydroxyethyl hydroperoxide (HEHP) formed from the reaction of anti- $\mathrm{CH}_{3} \mathrm{CHOO}+$ $\mathrm{H}_{2} \mathrm{O}$. These results agreed with the theoretical calculations since the TS barrier for the syn- $\mathrm{CH}_{3} \mathrm{CHOO}+\mathrm{H}_{2} \mathrm{O}$ pathway was 
higher than that for anti- $\mathrm{CH}_{3} \mathrm{CHOO}+\mathrm{H}_{2} \mathrm{O}$. These energy calculations for the $\mathrm{CH}_{3} \mathrm{CHOO}+\mathrm{H}_{2} \mathrm{O}$ reaction are almost identical to those reported in this work for the $\mathrm{CH}_{3} \mathrm{CHOO}+$ $\mathrm{CH}_{3} \mathrm{OH}$ reaction. However, the experimental results from the two studies are very different with no HEHP formed from syn$\mathrm{CH}_{3} \mathrm{CHOO}$ while $s$-MEHP-I is more abundant than $a$-MEHP-I. This could be explained, as mentioned before, considering a mediation of a third molecule in the reaction of $s y n-\mathrm{CH}_{3} \mathrm{CHOO}+$ $\mathrm{CH}_{3} \mathrm{OH}$ which does not occur in the syn- $\mathrm{CH}_{3} \mathrm{CHOO}+\mathrm{H}_{2} \mathrm{O}$ reaction.

The rotational transitions for both $a$-MEHP-I and $s$-MEHP-I conformers display $A-E$ splitting due to the internal rotation of only one methyl, despite the fact that two methyl groups exist in the MEHP molecule. Table 5 shows the theoretical values calculated for the $V_{3}$ barrier heights for the $\mathrm{O}-\mathrm{CH}_{3}$ methyl tops of $a$-MEHP-I and $s$-MEHP-I conformers. Those for the other $-\mathrm{CH}_{3}$ top, attached to the carbon atom, were calculated to be 938.0 and $783.9 \mathrm{~cm}^{-1}$ for $a$-MEHP-I and $s$-MEHP-I conformers, respectively. These values are too high to induce the appearance of internal rotation splittings. However, in the spectral analyses we considered both alternatives, $\mathrm{O}-\mathrm{CH}_{3}$ and $\mathrm{C}-\mathrm{CH}_{3}$, and only when we assigned the $A-E$ splitting to the $\mathrm{O}-\mathrm{CH}_{3}$ tops the results were reasonable. The analysis enabled us to determine the $V_{3}$ barrier heights together with some structural parameters such as $\delta$ and $\varepsilon$ (see Table 4). The agreement between the theoretical and experimental values is fairly good and confirms the assignment of the internal rotation splittings. The experimental $V_{3}$ barrier heights found for the $a$-MEHP-I and $s$-MEHP-I conformers are $650.8(36)$ and $549.00(37) \mathrm{cm}^{-1}$. The barrier height for $s$-MEHP-I is very similar to that determined for the MMHP-I conformer, 541.73(37) $\mathrm{cm}^{-1}$, which indicates that the surroundings for the methyl tops in both species are almost identical. In contrast, for $a$-MEHP-I the $V_{3}$ value is $\sim 20 \%$ larger than those for the $s$-MEHP-I and MMHP-I species. The steric hindrance caused by the orientation of the $\mathrm{C}-\mathrm{CH}_{3}$ methyl top in the $a$-MEHP-I species seems to be the main factor that enhances the internal rotation barrier height for this conformer.

\section{Conclusions}

In the present study, we reported the first direct spectroscopic detection of $\alpha$-methoxyalkyl hydroperoxides (MAHPs) as the nascent products from the atmospheric reactions between the $\mathrm{CH}_{2} \mathrm{OO}$ and $\mathrm{CH}_{3} \mathrm{CHOO}$ Criegee intermediates and methanol. Using FTMW spectroscopy supported by high level ab initio calculations, one and two conformers of methoxymethyl hydroperoxide (MMHP) and methoxyethyl hydroperoxide (MEHP), respectively, were identified in the gas phase. MMHP-I conformer is formed in the insertion reaction of $\mathrm{CH}_{2} \mathrm{OO}$ into the methanol $\mathrm{O}-\mathrm{H}$ bond, which is confirmed by isotopic substitution experiments. The non observation of further MMHP conformers is justified by kinetic and thermodynamic data and by the existence of conformational relaxation processes. Both anti and syn conformers of $\mathrm{CH}_{3} \mathrm{CHOO}$ react with methanol and produce the $a$-MEHP-I and $s$-MEHP-I conformers, respectively, being $s$-MEHP-I $\sim 2.6$ times more abundant than $a$-MEHP-I. These observed abundances cannot be explained by theory when only the bimolecular reaction paths of $s y n-\mathrm{CH}_{3} \mathrm{CHOO}+\mathrm{CH}_{3} \mathrm{OH}$ are considered. However, when the termolecular reaction of syn- $\mathrm{CH}_{3} \mathrm{CHOO}+2 \mathrm{CH}_{3} \mathrm{OH}$ is contemplated, the experimental observations may be understood. Although it is not clear whether methanol monomer or dimer can be attributed to the production of MEHP, rotational spectroscopy showed a critical evidence that MEHP is produced in similar ratios when syn- and anti- $\mathrm{CH}_{3} \mathrm{CHOO}$ react with methanol vapor.

\section{Conflicts of interest}

There are no conflicts to declare.

\section{Acknowledgements}

This research was supported by the Ministry of Science and Technology of Taiwan under Grant No. MOST 104-2113-M009-020 (Y. E.) and MOST 105-2811-M-009-026 and 106-2811M-009-023 (C. C.).

\section{References}

1 R. Criegee, Angew. Chem., Int. Ed. Engl., 1975, 14, 745-752.

2 J. M. Anglada, J. González and M. Torrent-Sucarrat, Phys. Chem. Chem. Phys., 2011, 13, 13034-13045.

3 K. E. Leather, M. R. McGillen, M. C. Cooke, S. R. Utembe, A. T. Archibald, M. E. Jenkin, R. G. Derwent, D. E. Shallcross and C. J. Percival, Atmos. Chem. Phys., 2012, 12, 469-479.

4 W. Chao, J. T. Hsieh, C. H. Chang and J. J. M. Lin, Science, 2015, 347, 751-754.

5 O. Welz, J. D. Savee, D. L. Osborn, S. S. Vasu, C. J. Percival, D. E. Shallcross and C. A. Taatjes, Science, 2012, 335, 204-207.

6 C. A. Taatjes, O. Welz, A. J. Eskola, J. D. Savee, A. M. Scheer, D. E. Shallcross, B. Rotavera, E. P. F. Lee, J. M. Dyke, D. K. W. Mok, D. L. Osborn and C. J. Percival, Science, 2013, 340, 177-180.

7 R. Chhantyal-Pun, A. Davey, D. E. Shallcross, C. J. Percival and A. J. Orr-Ewing, Phys. Chem. Chem. Phys., 2015, 17, 3617-3626.

8 O. Welz, A. J. Eskola, L. Sheps, B. Rotavera, J. D. Savee, A. M. Scheer, D. L. Osborn, D. Lowe, A. M. Booth, P. Xiao, M. A. H. Khan, C. J. Percival, D. E. Shallcross and C. A. Taatjes, Angew. Chem., Int. Ed., 2014, 53, 4547-4550.

9 R. Chhantyal-Pun, B. Rotavera, M. R. McGillen, M. A. H. Khan, A. J. Eskola, R. L. Caravan, L. Blacker, D. P. Tew, D. L. Osborn, C. J. Percival, C. A. Taatjes, D. E. Shallcross and A. J. Orr-Ewing, ACS Earth Space Chem., 2018, 2, 833-842.

10 P. D. Goldan, W. C. Kuster, F. C. Fehsenfeld and S. A. Montzka, Geophys. Res. Lett., 1993, 20, 1039-1042. 
11 A. Mellouki, T. J. Wallington and J. Chen, Chem. Rev., 2015, 115, 3984-4014.

12 M. Yang, P. D. Nightingale, R. Beale, P. S. Liss, B. Blomquist and C. Fairall, Proc. Natl. Acad. Sci. U. S. A., 2013, 110, 20034-20039.

13 H. B. Singh, M. Kanakidou, P. J. Crutzen and D. J. Jacob, Nature, 1995, 378, 50-54.

14 H. Singh, Y. Chen, A. Staudt, D. Jacob, D. Blake, B. Heikes and J. Snow, Nature, 2001, 410, 1078-1081.

15 D. B. Millet, D. J. Jacob, T. G. Custer, J. A. deGouw, A. H. Goldstein, T. Karl, H. B. Singh, B. C. Sive, R. W. Talbot, C. Warneke and J. Williams, Atmos. Chem. Phys., 2008, 8, 6887-6905.

16 P. Neeb, O. Horie and G. K. Moortgat, Int. J. Chem. Kinet., 1996, 28, 721-730.

17 J. H. Kroll and J. H. Seinfeld, Atmos. Environ., 2008, 42, 3593-3624.

18 M. A. Khan, C. J. Percival, R. L. Caravan, C. A. Taatjes and D. E. Shallcross, Environ. Sci.: Processes Impacts, 2018, 20, 437-453.

19 M. R. McGillen, B. F. E. Curchod, R. Chhantyal-Pun, J. M. Beames, N. Watson, M. A. H. Khan, L. McMahon, D. E. Shallcross and A. J. Orr-Ewing, ACS Earth Space Chem., 2017, 1, 664-672.

20 S. V. Tadayon, E. S. Foreman and C. Murray, J. Phys. Chem. A, 2018, 122, 258-268.

21 Y.-H. Lin, C. Yin, W.-H. Lin, Y.-L. Li, K. Takahashi and J. J. Lin, J. Phys. Chem. Lett., 2018, 9, 7040-7044.

22 W. Chao, Y.-H. Lin, C. Yin, W.-H. Lin, K. Takahashi and J. J. Lin, Phys. Chem. Chem. Phys., 2019, 21, 13633-13640.

23 G. J. R. Aroeira, A. S. Abbott, S. N. Elliott, J. M. Turney and H. F. Schaefer III, Phys. Chem. Chem. Phys., 2019, 23, 17760.

24 N. A. I. Watson, J. A. Black, T. M. Stonelake, P. J. Knowles and J. M. Beames, J. Phys. Chem. A, 2019, 123, 218-229.

25 T. H. Dunning, J. Chem. Phys., 1989, 90, 1007-1023.

26 J. Sun and K. Ruedenberg, J. Chem. Phys., 1993, 99, 5257-5268.

27 H.-J. Werner, P. J. Knowles, G. Knizia, F. R. Manby, M. Schütz, P. Celani, W. Györffy, D. Kats, T. Korona, R. Lindh, A. Mitrushenkov, G. Rauhut, K. R. Shamasundar, T. B. Adler, R. D. Amos, S. J. Bennie, A. Bernhardsson, A. Berning, D. L. Cooper, M. J. O. Deegan, A. J. Dobbyn, F. Eckert, E. Goll, C. Hampel, A. Hesselmann, G. Hetzer, T. Hrenar, G. Jansen, C. Köppl, S. J. R. Lee, Y. Liu, A. W. Lloyd, Q. Ma, R. A. Mata, A. J. May, S. J. McNicholas, W. Meyer, T. F. Miller III, M. E. Mura, A. Nicklaß, D. P. O’Neill, P. Palmieri, D. Peng, K. Pflüger, R. Pitzer, M. Reiher, T. Shiozaki, H. Stoll, A. J. Stone, R. Tarroni, T. Thorsteinsson,
M. Wang and M. Welborn, MOLPRO, version 2018.1, 2018, see http://www.molpro.net.

28 M. Kumar, D. H. Busch, B. Subramaniam and W. H. Thompson, Phys. Chem. Chem. Phys., 2014, 16, 22968-22973.

29 F. Liu, Y. Fang, M. Kumar, W. H. Thompson and M. I. Lester, Phys. Chem. Chem. Phys., 2015, 17, 20490-20494.

30 C. Cabezas and Y. Endo, Phys. Chem. Chem. Phys., 2020, 22, 446-454.

31 C. Cabezas, J.-C. Guillemin and Y. Endo, J. Chem. Phys., 2016, 145, 184304.

32 T. J. Balle and W. H. Flygare, Rev. Sci. Instrum., 1981, 52, 33-45.

33 Y. Hirahara, Y. Ohshima and Y. Endo, J. Chem. Phys., 1994, 101, 7342.

34 Y. Endo, H. Kohguchi and Y. Ohshima, Faraday Discuss., 1994, 97, 341-350.

35 Y. Sumiyoshi, H. Katsunuma, K. Suma and Y. Endo, J. Chem. Phys., 2005, 123, 054324.

36 M. Nakajima and Y. Endo, J. Chem. Phys., 2013, 139, 101103.

37 W. Gordy and R. L. Cook,Microwave Molecular Spectra, John Wiley Sons, New York, 1984.

38 H. Hartwig and H. Dreizler, Z. Naturforsch., 1996, 51a, 923-932.

39 R. C. Woods, J. Mol. Spectrosc., 1996, 21, 4-24.

40 M. Nakajima and Y. Endo, J. Chem. Phys., 2014, 140, 011101.

41 M. Nakajima, Q. Yue and Y. Endo, J. Mol. Spectrosc., 2015, 310, 109-112.

42 R. S. Ruoff, T. D. Klots, T. Emilsson and H. S. Gutowsky, J. Chem. Phys., 1990, 93, 3142-3150.

43 C. Cabezas, J.-C. Guillemin and Y. Endo, J. Chem. Phys., 2018, 149, 084309.

44 M. Nakajima and Y. Endo, J. Chem. Phys., 2014, 140, 134302. 45 M. Nakajima and Y. Endo, J. Chem. Phys., 2015, 143, 164307. 46 J. M. Anglada and A. Solé, Phys. Chem. Chem. Phys., 2016, 18, 17698-17712.

47 M. C. Smith, C.-H. Chang, W. Chao, L.-C. Lin, K. Takahashi, K. A. Boering and J. J.-M. Lin, J. Phys. Chem. Lett., 2015, 6, 2708-2713.

48 L. Sheps, B. Rotavera, A. J. Eskola, D. L. Osborn, C. A. Taatjes, K. Au, D. E. Shallcross, M. A. H. Khan and C. J. Percival, Phys. Chem. Chem. Phys., 2017, 19, 21970-21979.

49 R. A. Motiyenko, L. Margulès, D. Despois and J.-C. Guillemin, Phys. Chem. Chem. Phys., 2018, 20, 5509-5516.

50 L.-C. Lin, W. Chao, C.-H. Chang, K. Takahashi and J. J.-M. Lin, Phys. Chem. Chem. Phys., 2016, 18, 28189-28197.

51 C. Cabezas and Y. Endo, J. Chem. Phys., 2018, 148, 014308. 